\title{
ESTRATÉGIA COMO PRÁTICA E APRENDIZAGEM NA INTERAÇÃO DOS SUJEITOS RECICLADORES: RESULTADOS DA INCUBADORA DE EMPREENDIMENTOS SOLIDÁRIOS, DO CENTRO UNIVERSITÁRIO LA SALLE, CANOAS, RS
}

\author{
STRATEGY AS PRACTICE AND LEARNING ON THE \\ INTERACTION BETWEEN RECYCLERS SUBJECTS: \\ SOLIDARITY PROJECT INCUBATOR RESULTS
}

Recebido: 04-03-2013 Aceite: 15/10/2014

Robinson Henrique Scholz ${ }^{1}$ Graciema Fátima da Rosa² Maria de Lourdes Borges ${ }^{3}$

\section{RESUMO}

Este artigo pretende analisar as estratégias como práticas e a aprendizagem dos sujeitos em interação no âmbito da Incubadora de Empreendimentos Solidários, do Centro Universitário La Salle (Unilasalle), Canoas, Rio Grande do Sul (RS), juntamente aos sete empreendimentos incubados. A análise socioambiental crítica sobre os processos de atuação consiste no ponto de partida; os empreendimentos incubados, por sua vez, atuam na área da reciclagem de resíduos pós-consumo, localizados nos municípios de Canoas, Esteio e Nova Santa Rita, no RS. O método de investigação adotado é um estudo multicasos, de cunho qualitativo, enquanto o corpus de dados é composto por 15 entrevistas semiestruturadas realizadas com os catadores participantes dos empreendimentos incubados, por observações participantes e por dois grupos focais. Para a análise e o tratamento dos dados coletados, o método adotado é a análise de conteúdo. Os resultados indicam que: i) a atuação da Incubadora é avaliada como sendo propulsora de políticas públicas por meio dos processos democráticos de participação; ii) a construção dos processos de aprendizagem foi realizada por meio da educação popular; iii) há necessidade de ampliação da ação da Incubadora para além dos empreendimentos incubados, na busca de redes de cooperação para o fortalecimento da cadeia produtiva da reciclagem, intentando o beneficiamento dos resíduos e a comercialização conjunta, por exemplo.

Palavras-chave: Estratégia como Prática, Empreendimento de Reciclagem, Aprendizagem Socioambiental, Economia Solidária, Incubadora.

1 Possui graduação em Administração de Recursos Humanos pela Universidade do Vale do Rio dos Sinos - UNISINOS. Mestrado em Ciências Sociais pela Universidade do Vale do Rio dos Sinos - UNISINOS. Atualmente é doutorando em Ciências Socias pela Universidade do Vale do Rio dos Sinos - UNISINOS. Canoas, Rio Grande do Sul. Brasil. Email: robinsonscholz@hotmail.com

2 Possui graduação em Psicologia pela Universidade do Vale do Rio dos Sinos - UNISINOS. Mestrado em Educação pela Universidade Federal do Rio Grande do Sul - UFRGS. Atualmente é professora de Psicologia, Administração e Tecnólogos da UNILASALLE. Canoas, Rio Grande do Sul. Brasil. Email: graciemarosa@terra.com.br

3 Possui graduação em Psicologia pela Universidade do Vale do Rio dos Sinos - UNISINOS. Mestrado e doutorado em Administração pela Universidade do Vale do Rio dos Sinos - UNISINOS. Atualmente é professora no Centro Universitário UNILASALLE. Canoas, Rio Grande do Sul. Brasil. Email: maluborg@gmail.com 
ESTRATÉGIA COMO PRÁTICA E APRENDIZAGEM NA INTERAÇÃO DOS SUJEITOS RECICLADORES: RESULTADOS DA INCUBADORA DE EMPREENDIMENTOS SOLIDÁRIOS, DO CENTRO UNIVERSITÁRIO LA SALLE, CANOAS, RS

\section{ABSTRACT}

This article intends to analyze the strategies and subjects practices and learning in interaction within the Entrepreneurial Incubator Solidarity at the Centro Universitário La Salle - Unilasalle Canoas/RS, per seven incubated enterprises. The critical environmental process is acting point of analysis. The incubated enterprises operating in the recycling of post-consumer waste in the municipalities of Canoas, Esteio and Nova Santa Rita, Rio Grande do Sul, Brazil. The research method adopted is a multi-case study, a qualitative path. The data corpus is composed of 15 semistructured interviews with the participants of scavengers incubated enterprises, participant observations, and two focus groups. For the analysis and processing of data collected, the method used is content analysis. The results indicate that: i) the performance of the Incubator is assessed as driving public policy through the democratic processes of participation, ii) construction of learning processes were carried out through popular education, iii) there is a need to expand the action Incubator beyond the incubated enterprises, seeking cooperation networks to strengthen the supply chain of recycling, intending the processing of waste, joint marketing, among others.

Keywords: Strategy as Practice, Enterprise Recycling, Social Environmental Learning, Social Economy, Incubator.

\section{INTRODUÇÃO}

Os processos de atuação de uma Incubadora de Empreendimentos Solidários perpassam um campo significativo de práticas de monitoramento e assessoria que vão além das fronteiras empreendedoras no campo da economia solidária. As ações são realizadas nas esferas públicas das relações sociais e da articulação com as políticas públicas e operam no âmbito coletivo dos empreendimentos na perspectiva da educação para a autogestão, produção e comercialização dos bens e serviços produzidos, sustentabilidade etc.

O campo relacional que uma Incubadora Universitária Tecnológica de Cooperativas Populares (ITCP) tem a desenvolver requer um espaço de aplicação estratégica para a condução do seu trabalho de assessoria. Esse espaço de aplicação estratégica, por sua vez, envolve ações como capacitações para os cooperados, formalização do empreendimento, geração de trabalho e renda por meio de políticas públicas, responsabilidade socioambiental, entre outras (FRANÇA FILHO; CUNHA, 2009).

Para uma melhor compreensão dessa temática, este artigo busca analisar as estratégias como práticas e a aprendizagem dos sujeitos em interação no âmbito de desempenho da Incubadora de Empreendimentos Solidários, do Centro Universitário La Salle (Unilasalle), Canoas, $\mathrm{RS}$, a fim de compreender os mecanismos de contribuição para o desenvolvimento da economia solidária no seu território socioambiental de atuação, por meio da incubação de sete empreendimentos de reciclagem de resíduos sólidos urbanos.

Para isso, o presente artigo está estruturado da seguinte maneira: inicialmente, apresentam-se os aspectos teóricos da estratégica como prática no contexto de incubadoras populares. Em seguida, discute-se a proposta de atuação das ITCPs e sua relação com a economia solidária. Após, o método é descrito, contendo uma contextualização dos empreendimentos incubados. Por fim, procede-se à análise dos dados sistematizados e dos resultados relevantes do estudo.

\section{ESTRATÉGIA COMO PRÁTICA}

Com o desenvolvimento das ciências, o conceito de estratégia passa a ser mais interdisciplinar, englobando a necessidade de analisar os mecanismos de interação dos indivíduos para o alcance de objetivos, que vão além dos econômicos (WILSON; JARZABKOWSKI, 2004; WHITTINGTON, 2004). De acordo com essa perspectiva, a estratégia pode ser estudada e praticada sob 
diversas possibilidades, devido ao seu alto grau de complexidade.

É possível, assim, diferentes formatos organizacionais e institucionais conseguirem sobreviver no mercado ou à margem dele sem ao menos ter planos estratégicos predefinidos? Segundo a epistemologia positivista e funcionalista, a resposta a essa pergunta é negativa, pois as organizações são definidas segundo suas estruturas e seus objetivos organizacionais estabelecidos a priori (WILSON; JARZABKOWSKI, 2004). Já sob a perspectiva da abordagem processual da estratégia, a resposta é sim, pois esta vem para questionar a maneira como organizações e instituições realizam ações que resultam na estratégia como prática, uma vez que, nesse entendimento, não existe divisibilidade entre planejamento e implementação.

Ambos os processos possuem uma "interrelação mutuamente sustentada" (WILSON; JARZABKOWSKI, 2004, p. 13). Em outras palavras, a interação entre o pensar e o agir estrategicamente manifesta-se por meio da linguagem e da consequente mobilização de recursos que ocorre quase concomitantemente. Ainda segundo Wilson e Jarzabkowski (2004), o pensar e o agir estratégico ocorrem de maneira oscilatória e não linear, formando o fazer estratégia. Tal fazer estratégia pode ser entendido "como uma mistura de ação (animação) e direção (orientação)", de modo que a ação e a direção tornam-se partes do entendimento da estratégia como prática (WILSON; JARZABKOWSKI, 2004, p. 13). Assim, estratégia como prática pode ser considerada como uma prática social.

Como prática social, interessa à estratégia como prática compreender o fazer estratégia, o que implica várias atividades, tais como a separação do material a ser reciclado, a maneira como negociam com compradores do material reciclado, o preenchimento de documentos, as reuniões, o modo como o planejamento se desenrola ao longo do ano etc. Além disso, interessam as questões como conhecimento tácito e formal, persistência nos detalhes e conhecimento técnico e interpessoal. Por isso, não existe uma estratégia igual a outra, pois o modo como às coisas são feitas é o que mais interessa, sendo necessário levar em conta, por exemplo, os papéis distintos entre organizações, o conhecimento dentro do contexto que interfere nas competências práticas, as quais podem se distanciar mais ou menos da habilidade na elaboração da estratégia (WHITTINGTON, 1996).

Segundo Whittington (1996), a estratégia como prática se traduz em atividades "pouco românticas" de gestão, incluindo a busca do entendimento de questões como: o que todos os envolvidos fazem e como eles adquirem habilidades? Tais questões referem-se à maneira como os indivíduos trabalham as rotinas para fazer estratégia. $O$ foco sai do desempenho da organização ou instituição e vai para o desempenho dos estrategistas, que são, em última instância, todos os seus componentes.

Para Wilson e Jarzabkowski (2004), no estudo da estratégia como prática, torna-se importante definir o seu nível e a sua unidade de análise. Os níveis de análise envolvem os níveis micro e macrorrelevantes para a estratégia como prática: o nível macro envolve as instituições sociais, econômicas e políticas enquanto o nível micro abrange discursos, atos, pensamentos e gestos dos praticantes. Os autores salientam que ambos os níveis "coexistem em uma tensão relacional de constituição e explicação mútua, interagindo por meio de uma gama de fatores intermediários" (WILSON; JARZABKOWSKI, 2004, p. 13). Já a unidade de análise deve ser aquela que gera algum resultado a ser analisado. É nessa linha que as unidades de análise serão desdobradas.

\section{APRENDIZAGEM}

A aprendizagem ocorre a partir das experiências dos sujeitos enquanto fazem a estratégia como prática. Para Fiol e Lyles (1985), a aprendizagem tem importância estratégica como processo de ações de melhoria que amplia o conhecimento e a compreensão, implicando melhoria dos resultados organizacionais. Portanto, a aprendizagem organizacional permite que a empresa 
ESTRATÉGIA COMO PRÁTICA E APRENDIZAGEM NA INTERAÇÃO DOS SUJEITOS RECICLADORES: RESULTADOS DA INCUBADORA DE EMPREENDIMENTOS SOLIDÁRIOS, DO CENTRO UNIVERSITÁRIO LA SALLE, CANOAS, RS

construa uma interpretação e um entendimento do ambiente de onde está inserida, possibilitando avaliação de estratégias viáveis (FIOL; LYLES, 1985).

Nesse campo de experimentação do trabalho, tendo as cooperativas de reciclagem como objeto de estudo, é que a educação toma corpo e força, com argumentos significativos para a pesquisa e formulações inovadoras em educação e gestão socioambiental (FISCHER, 2009). Além disso, as instituições que não mudarem sua postura na sociedade e, sobretudo por não privilegiar a melhor utilização dos recursos naturais, terão sua imagem corporativa ameaçada perante a sociedade (LEITE, 2009). Evidentemente, o consumo realizado por indivíduos educados e instruídos para a sustentabilidade tende a se voltar para produtos e serviços de instituições que investem na gestão socioambiental. Nesse sentido, salienta-se que a comunicação é essencial para que se apreendam competências requeridas no tocante à aprendizagem e à compreensão da autonomia do sujeito de poder potencializar suas práticas, intentando ao habitus (BOURDIEU, 2007), além de seu caráter problematizador e transformador.

A construção dos vínculos estabelecidos por meio da linguagem e da apropriação da aprendizagem, a qual pode gerar o habitus, o que busca o diálogo, em qualquer hipótese (seja em torno de um conhecimento científico e técnico, seja em torno de um conhecimento experimental), é um meio da problematização do próprio conhecimento em sua indiscutível relação com a realidade concreta, na qual incide para melhor compreendê-la, explicá-la e transformá-la (FREIRE, 2004, p. 97). Essa capacidade transformadora está no escopo de ação das estratégias, uma vez que objetivos a serem alcançados implicam a busca de mudanças sociais, comportamentais, políticas etc. Tais mudanças nos comportamentos geram novas relações comunitárias na teia social dos territórios, no sentido de poder projetar a transformação socioambiental, aqui entendida, também, como educação.

Por outro lado, Crossan et al. (1999) consideram que a aprendizagem é um meio de alcançar o que chamam de renovação estratégica, motivo pelo qual esses autores desenvolveram um modelo para o processo da aprendizagem organizacional. Esta estrutura de aprendizagem apresenta quatro premissas: (i) da tensão permanente entre exploration (nova aprendizagem) e exploitation (antiga aprendizagem); (ii) da aprendizagem multinível (individual, grupal e organizacional), (iii) de que esses níveis interagem com os processos sociais e psicológicos da intuição, interpretação, integração e institucionalização; e (iv) de que a cognição afeta a ação e vice-versa. Torna-se importante enfatizar que, para Weick e Westley (2004), a aprendizagem organizacional tanto é um resultado quanto um processo. A aprendizagem depende dos indivíduos, embora não seja exclusividade destes, pois ocorre também nas estruturas organizacionais, tais como a cultura que aparece na linguagem (palavras, frases, vocábulos e expressões que os grupos desenvolvem), nos artefatos e nos objetos materiais que um grupo produz.

Para que a discussão seja compreendida de melhor forma no contexto da pesquisa deste artigo, na seção a seguir, é contextualizado o campo da economia solidária e das ITCPs.

\section{AS ITCPS E A SUA ATUAÇÃO NA ECONOMIA SOLIDÁRIA}

Os programas sociais desenvolvidos pelo governo brasileiro a partir de 2002 são um desafio para a redução das desigualdades. Os estudos, as políticas e as práticas intensificaram-se nos últimos anos, assim como as iniciativas populares que reagem à exclusão social e proliferam em todo o país. As experiências de economia solidária promovem a geração de trabalho e renda em diversos contextos sociais, urbanos e rurais. Contudo, essas iniciativas não alcançam êxito de forma isolada, necessitando de incentivos provenientes de políticas socioeconômicas que possi- 
bilitem o desenvolvimento da economia solidária. Uma consideração a ser feita sobre as políticas sociais de redistribuição de renda no Brasil é de que está comprovada a ineficácia do crescimento econômico como fator de distribuição de riqueza, motivo pelo qual são criados programas de transferência de renda como alternativa para a redução das desigualdades (GAIGER, 2011).Nessa dinâmica socioeconômica, há, por outro lado, a relação com o mercado neoliberal, que estimula o consumo e a geração de riquezas por parte dos mais ricos. Isso gera manifestações antagônicas no cotidiano brasileiro, resultando um déficit social, mesmo com as políticas de redistribuição: "nota-se o aparecimento de uma nova forma de reprodução da pobreza, cada vez mais concentrada no segmento da população que se encontra ativa no interior do mercado de trabalho" (ANTUNES e POCHMANN, 2007, p. 206). Contingentes de trabalhadores estão à mercê da sorte procurando oportunidades de emprego formal no mercado de trabalho, muitas vezes temporárias e precarizadas, para poderem se estabelecer como sujeitos sociais (LOPES, 2008). Uma expressiva quantidade de trabalhadores em condição de vulnerabilidade sedimenta a zona de tensão entre o desemprego e integração no mercado de trabalho. Como enfrentamento desse cenário relacionado ao trabalho surge a economia solidária como uma possível alternativa de geração de renda e integração econômica - aqui não identificando lógicas puras de inclusão social por meio de um contrato formal de trabalho, mas sim a ativação econômica dos trabalhadores vulnerabilizados.

Os estudos sobre a economia solidária merecem destaque, pois "os membros de tais iniciativas estabelecem entre si vínculos de reciprocidade como um dos fundamentos de suas relações de cooperação [...] cumprindo funções subsidiárias em domínios como saúde, educação e preservação ambiental” (GAIGER, 2011, p. 80). Ainda segundo este autor, os trabalhadores que se valem da economia solidária operam em cenários que também são sociais: a) melhorias das condições de moradia e convívio social; b) discussão junto ao Estado sobre o desenvolvimento de políticas públicas que beneficiem o território local; e c) potencialização do uso de produtos sustentáveis e/ou que não venham a agredir o meio ambiente. Considerando a atuação política relacional que a economia solidária também discute em suas práticas, Asseburg e Gaiger (2007, p. 528) afirmam que "reside na mudança e no bem que acarretam para os seus próprios protagonistas, ao escaparem da lógica dominante de classificação social".

Assim, pode-se entender que as práticas associativas de geração de trabalho e renda, incorporadas a práticas autogestionárias nos empreendimentos de econômicos solidários, podem (re)afirmar o espaço social, sedimentando processos estruturados de subsistência para além das fronteiras econômicas, já que suas contribuições atingem as esferas sociais, políticas e ambientais para a superação das desigualdades.

A produção autogestionária no Brasil estabelece a sua história como um movimento social no país, pois, a despeito do mercado restrito e dos (ainda) relativamente poucos segmentos trabalhados, vem crescendo significativamente e tomando forma de movimento social ao articular diversos atores que lutam por transformações no campo social e político (VERONESE, 2004).A economia solidária é regida por medidas diversificadas de acordo com cada empreendimento, seguindo aproximadamente oito princípios: autogestão, democracia, participação, igualitarismo, cooperação, autossustentação, desenvolvimento humano e responsabilidade social (GAIGER, 2004). Igualmente, a economia solidária valoriza o território e compromete-se com a localidade prioritariamente presente no mercado intra-regional, procurando uma forma apropriada de uso do capital natural compatível com a melhor qualidade de vida da população residente, isto é, consiste em um vetor de desenvolvimento endógeno e sustentável (LISBOA, 2001).

Potencialidades locais adormecidas estimuladas por meio da economia solidária podem gerar o crescimento local e sustentável. O desenvolvimento de pesquisas, análises, ações e práti- 
cas voltadas para o desenvolvimento socioambiental de trabalhadores imersos nas camadas marginalizadas da sociedade requer um aprofundamento nesse campo relacional e de disputas, aqui entendido na esfera pública de relações coletivas de trabalho, os quais materializam suas práticas em grupos informais, associações e cooperativas de reciclagem de resíduos sólidos urbanos.

Portanto, tendo como orientação este campo de experimentação, as incubadoras universitárias que atuam com tecnologias para o desenvolvimento de cooperativas e empreendimentos solidários requerem demandas significativas na consolidação destes coletivos. Essas incubadoras desenvolvem assessoria aos empreendimentos que estão em incubação, atuando em diversas esferas, tais como: capacitação, incubação, assessoria técnica e organizativa (BRASIL, 2007).

Para uma melhor compreensão sobre o papel de atuação das ITCPs, os autores França Filho e Cunha (2009) descrevem as principais atuações no campo da economia solidária: 1) capacitar os sócios dos empreendimentos para que saiam da informalidade e tenham uma renda digna; 2) articular políticas públicas para a geração de trabalho e renda; e 3) organizar as próprias ITCPs, que vêm se congregando por meio de redes nacionais. Criadas em 1999, com o objetivo de desenvolver e disseminar conhecimentos sobre cooperativismo e autogestão, a Rede de Incubadoras Tecnológicas de Cooperativas Populares (Rede ITCPs) contribui para o desenvolvimento da economia solidária. Surgem, assim, para integrar de forma dinâmica as incubadoras e favorecer a transferência de tecnologias sociais e de conhecimentos.

Ressalta-se, ainda, que os processos de incubação das cooperativas incubadas ocorrem no local de trabalho, ou seja, a incubação ocorre na sede dos empreendimentos e não em uma estrutura física da incubadora, processo esse distinto das lógicas de atuação das incubadoras empresariais. Diante disso, Della Vechia et. al. (2011, p. 116) esclarecem a proposta de uma ITCP no seu espaço de atuação universitária, bem como sua funcionalidade:

Uma ITCP é uma unidade acadêmica interdisciplinar de ensino, pesquisa e extensão, cujo objetivo é fazer interagir o meio universitário e os grupos de trabalhadores/as, que tentam empreender economicamente de forma coletiva solidária e autogestionária - de maneira a apoiar a formação e a consolidação dos empreendimentos e, ao mesmo tempo, transformar a universidade, aproximando-a dos interesses, desejos e necessidades dos setores populares. Isso é feito através de um processo intenso de troca de conhecimentos práticos e teóricos e de uma construção compartilhada de novos conhecimentos, entre a incubadora e os grupos de trabalhadores associados.

Essa possibilidade de interação e trocas de experiências entre o universo acadêmico e as práticas populares de trabalho realizadas pelas cooperativas suscita metodologias apropriadas para a condução das ações de incubação. Assim, a comunicação é essencial para que se apreendam competências requeridas no tocante à cooperação e à compreensão da autonomia do sujeito (associado da cooperativa) de poder potencializar suas práticas apreendidas, além de ser problematizadora e transformadora:

O que busca com o diálogo, em qualquer hipótese (seja em torno de um conhecimento científico e técnico, seja de um conhecimento experimental) é a problematização do próprio conhecimento em sua indiscutível relação com a realidade concreta, na qual incide para melhor compreendê-la, explicá-la, transformá-la (FREIRE, 2004, p. 97). 
A partir dessa problematização proposta pelos estudos da educação popular freiriana, pode-se ampliar o entendimento do papel de atuação das ITCPs, as quais "são agentes de um processo educativo para a cooperação e autogestão, constituindo-se como projetos, programas ou órgãos com a finalidade de dar suporte à formação e ao desenvolvimento de cooperativas populares" (MEIRELES; ALVES, 2011, p. 9). Assim, fortalecer essas iniciativas para o trabalho cooperado e autogestionário conduz à construção de saberes e competências para a atuação no campo da economia solidária nas dimensões sociais e econômicas.

As potencialidades de cada empreendimento incubado merecem ser valorizadas. As singularidades e os saberes existentes na esteira de cada lógica de ação em relação com o seu contexto cultural possibilitam as distinções de cada coletivo, bem como a elaboração das tecnologias sociais. Assim, segundo Cançado e Cançado (2009), a metodologia de incubação fundamenta-se em quatro premissas: 1) a não redução da autonomia do grupo; 2) a velocidade do processo de incubação decidida pelo grupo; 3) a veracidade das medições; e 4) o feedback fornecido ao grupo.

Diante dessas práticas de incubação, os processos dialógicos de trabalho com os empreendimentos tornam-se fundamentais para o fortalecimento dos vínculos de confiança, bem como para avanços na autonomia dos associados (nos campos formativos, na gestão e articulação com as políticas públicas) perante a atuação da ITCPs. Isso possibilita a pós-incubação ou a constituição de redes de cooperação, entendida como a reunião "de empreendimentos com objetivos comuns, densamente inter-relacionados, estando estruturada para desenvolver e manter ganhos coletivos, sem que cada participante venha a perder sua autonomia de gestão" (BALESTRIN; VERSCHOORE, 2008, p. 24).

Quando olhados os processos de estratégia como prática dentro de cooperativas de reciclagem, faz sentido o seu estudo, uma vez que nesses ambientes a ação e a direção estratégicas ocorrem no fazer dos cooperativados em todos os momentos do seu trabalho. Tais momentos referem-se ao desenvolvimento de soluções e problemas cotidianos revelados nas práticas dos cooperativados (WHITTINGTON, 2004). Nesse sentido, como já citado anteriormente, a estratégia como prática pode ser considerada uma prática social.

A prática social que pode estar representada na estratégia como prática no contexto de ITCPs envolve, além da dimensão econômica, a dimensão social. A dimensão econômica engloba a geração do trabalho e da renda, e a dimensão social, sob um aspecto micro, ocorre por meio das interações sociais que proporcionam a estruturação para a realização do trabalho, que é, em última instância, a estratégia como prática.

Além disso, outro aspecto que aproxima o estudo da estratégia como prática do contexto de atuação das ITCPs é o empoderamento dos trabalhadores (e/ou incubados) como agentes capazes de realizar uma mudança no contexto em que atuam. Nesse sentido, uma das dimensões que a estratégia como prática assume é, com base na perspectiva aristotélica, "sobre a sabedoria da prática como um exercício localizado de julgamento", que envolve a capacidade da realização do trabalho no contexto e nas contingências específicas e necessárias para o aqui e agora (WILSON; JARZABKOWSKI, 2004, p. 15). Ainda segundo os mesmos autores, a sabedoria da prática relaciona aspectos da ação e da direção estratégicas como um exercício de julgamentos em tempo real. A necessidade desse tipo de julgamento ocorrem em função do contexto repleto de ambiguidade, incerteza e conflito em que, muitas vezes, meios e fins se contradizem e em que consequências não intencionais exigem mudanças de ação e direção.

Nos contextos das incubadoras populares, não diferentemente do contexto dos outros formatos de organização, mesmo quando é projetado um plano estratégico para o futuro, é impossível prever o resultado. Por isso, torna-se importante que todos os integrantes das organiza- 
ções e das incubadoras voltem-se para o fluxo de trabalho, pois, ao se mover na direção do que foi planejado, baseiam-se nos recursos existentes (WILSON; JARZABKOWSKI, 2004) e decidam com base neles, no aqui e agora. Nesse sentido, há a necessidade de que os "atores organizacionais" reflitam sobre suas "ações atuais dentro do contexto das ações passadas e das aspirações futuras, e que façam a mediação entre as duas coisas de forma a poder desafiar e transformar a prática existente" (WILSON; JARZABKOWSKI, 2004, p. 15). Cabe às ITCPs fomentarem esse tipo de reflexão para fortalecer o empoderamento dos atores socioambientais a fim de que se tornem agentes de sua vida e da sociedade.

\section{MÉTODO}

Este artigo tem por objetivo refletir sobre as estratégias como práticas desenvolvidas pela Incubadora de Empreendimentos Solidários junto aos empreendimentos incubados. A Incubadora é um projeto fomentado pela Financiadora de Estudos e Projetos (FINEP) por meio de um convênio firmado entre o Ministério da Ciência, Tecnologia e Inovação (MCTI), o Ministério do Trabalho e Emprego (MTE) e a Secretaria Nacional de Economia Solidária (SENAES). Desde 2008, o projeto vem desenvolvendo suas ações de assessoria e fomento a empreendimentos econômicos solidários localizados nos municípios gaúchos de Canoas, Esteio e Nova Santa Rita, intensificando o processo de incubação de associações e cooperativas de trabalho atuantes na área da reciclagem de resíduos pós-consumo.

A Incubadora de Empreendimentos Solidários está localizada no Tecnosocial/Unilasalle, o qual consolida uma das ações do Centro Universitário La Salle (Unilasalle) que objetiva contribuir para o fortalecimento de empreendimentos de economia solidária de Canoas e região na perspectiva de construir tecnologias sociais apropriadas para fortalecer a capacidade empreendedora e a dinâmica solidária desses empreendimentos, potencializando sua atuação sustentável e autogestionária nos territórios onde atuam. O convênio com a FINEP possibilita o desenvolvimento de ações com os empreendimentos incubados, com os fóruns de economia solidária e com o desenvolvimento do trabalho autogestionário, ou seja, o monitoramento e a assessoria para gestão, produção, comercialização, formação etc. Assim, para que se possam buscar soluções para as variadas demandas nos empreendimentos incubados, a equipe pretende ampliar o envolvimento de professores e estudantes das diversas áreas do conhecimento, integrando ensino, pesquisa e extensão.

Para a compreensão do objeto de pesquisa, o método adotado é um estudo de casos múltiplos (YIN, 2005) com abordagem qualitativa. O corpus de dados é composto por 15 entrevistas semiestruturadas com os sujeitos dos empreendimentos de reciclagem, por registros de observações de campo e por dois grupos focais (GIL, 1999; BAUER E AARTS, 2002; ROESCH, 2005;). A técnica de tratamento e análise dos dados adotada foi a análise de conteúdo (BARDIN, 1977).

Para uma melhor contextualização dos empreendimentos investigados nesta pesquisa, são apresentados os sete empreendimentos que participaram no processo das coletas de entrevistas realizadas pelos autores deste artigo que não estão vinculados diretamente na equipe da Incubadora. Essa estratégia foi adotada para obter melhor acuidade nas respostas, neutralizando a equipe nesta etapa para não influenciar os catadores/as respondentes. Salienta-se que apenas um empreendimento não participou do processo de coleta das entrevistas, que foi a Associação dos Trabalhadores Prestadores de Serviço, Catadores e Reciclagem de Nova Santa Rita (ATPSCR). Contudo, fizeram parte dos processos de observações realizadas. Diante disso, o Quadro 01 apresenta uma contextualização de cada empreendimento. 
Quadro 01: Contextualização dos Empreendimentos Incubados

\begin{tabular}{|c|c|c|c|c|}
\hline COOPCAMATE & 1986 & 21 & Canoas/RS & $\begin{array}{c}\text { Iniciou com cinco pessoas , para a realização da coleta de } \\
\text { resíduos no bairro. }\end{array}$ \\
\hline COOARLAS & 2000 & 32 & Canoas/RS & $\begin{array}{c}\text { Doze mulheres catavam o lixo da comunidade puxando carrinhos } \\
\text { em um raio de } 500 \text { metros. A triagem era realizada em uma } \\
\text { garagem de } 9 \mathrm{~m}^{2} \text {, cedida por uma dessas mulheres. }\end{array}$ \\
\hline RENASCER & 1983 & 34 & Canoas/RS & $\begin{array}{c}\text { A origem deu-se através de um grupo de catadores que } \\
\text { catavam no aterro Municipal de Canoas. }\end{array}$ \\
\hline COOPERSOL & 2009 & 8 & Canoas/RS & $\begin{array}{c}\text { A origem do trabalho coletivo se deu a partir da catação } \\
\text { individual que era feita no aterro de construção civil da cidade de } \\
\text { Canoas. }\end{array}$ \\
\hline COOPERMAG & 2002 & 23 & Canoas/RS & $\begin{array}{c}\text { Surgiu a partir da necessidade de encontrar uma alternativa para } \\
\text { a geração de trabalho e renda para mulheres da comunidade } \\
\text { Santa Rita, no Bairro Mato Grande. }\end{array}$ \\
\hline ATPSCR & 2005 & 10 & Nova Santa Rita/RS & $\begin{array}{c}\text { grupo foi constituído visando à geração de trabalho e renda de } \\
\text { catadores envolvidos. }\end{array}$ \\
\hline
\end{tabular}

Fonte: elaborado pelos autores.

As temporalidades de cada empreendimento econômico solidário são diversas, com origens e contextos distintos, os quais são apresentados a seguir:

COOTRE - a Associação de Recicladores e Catadores de Esteio (ARCA), foi fundada no ano de 2003, tendo como sede a Associação de Moradores do Bairro Votorantin. No decorrer do ano de 2005, transferiu-se para o Centro de Triagem pertencente à Secretaria Municipal de Meio Ambiente localizada na cidade de Esteio, RS. Desde sua fundação, a ARCA realiza a coleta seletiva na cidade, porém, apenas em 2012, foi reconhecida como prestadora de serviço pela Prefeitura Municipal de Esteio. Em 2012, torna-se cooperativa com o nome de Cooperativa de Trabalho de Recicladores de Esteio (COOTRE);

COOPCAMATE - fundada em 1986 para a realização da coleta de resíduos sólidos urbanos no bairro Mathias Velho (Canoas, RS), com coleta em colégios e igrejas com apoio das Comunidades Eclesiais de Base (CEBs). Na época se chamava Associação dos Carroceiros e Catadores de Material de Canoas (ACCMC). Em 2002, fundou a Cooperativa de Catadores de Material Reciclável da Mathias Velho (COOPCAMATE), para a formalização de um contrato para receber os materiais de uma grande empresa. Em 2010, a COOPCAMATE, mesma cooperativa que já recebia a coleta seletiva da cidade, foi contratada pela prefeitura para participar do Programa de Coleta Seletiva Compartilhada de Canoas, que consiste no recebimento de verba pública, por meio de contrato, para o transporte dos materiais das residências até a cooperativa;

COOARLAS - no ano de 2000, 12 mulheres iniciaram a coleta no bairro Guajuviras ( $\mathrm{Ca}$ noas, RS) e a triagem dos materiais em uma pequena garagem. Neste mesmo ano, essas muIheres formalizaram a associação, que se chamou Associação de Reciclagem Amigas Solidárias (ARLAS), além de mobilizarem-se na comunidade para a captação de recursos do Orçamento Participativo do RS, com o qual puderam construir a sua sede de trabalho. Em 2009, fundaram a Cooperativa de Trabalho Amigas e Amigos Solidários (COOARLAS). Em 2010, inicia sua participação no Programa de Coleta Seletiva Compartilhada de Canoas, juntamente com a COOPCAMATE;

RENASCER - a origem do trabalho coletivo data de meados de 1983, período em que se deu a catação de materiais recicláveis no aterro sanitário do município de Canoas, RS. No ano de 2005, o "grupo do aterro" foi impedido pela Fundação Estadual de Proteção Ambiental (FEPAM) de catar materiais no aterro sanitário. Então, passaram a ocupar um telhado improvisado e a receber parte da coleta seletiva do município de Canoas para a realização da triagem. A Cooperativa de Reciclagem Renascer foi constituída juridicamente em 2010, ano em que foram contra- 
ESTRATÉGIA COMO PRÁTICA E APRENDIZAGEM NA INTERAÇÃO DOS SUJEITOS RECICLADORES: RESULTADOS DA INCUBADORA DE EMPREENDIMENTOS SOLIDÁRIOS, DO CENTRO UNIVERSITÁRIO LA SALLE, CANOAS, RS

tados para participar do Programa de Coleta Seletiva Compartilhada de Canoas, juntamente com a COOARLAS E A COOPCAMATE;

COOPERSOL - a origem do trabalho coletivo ocorreu a partir da catação individual que era realizada no aterro de construção civil da cidade de Canoas, RS. Em 2009, buscando perspectivas de melhorias de sustentabilidade a partir do trabalho organizado, formalizaram a Associação Sol Nascente. Em 2012, regularizaram-se como Cooperativa dos Recicladores de Resíduos Sólidos Sol Nascente (COOPERSOL). Também em 2012 o grupo recebeu um galpão de madeira da Prefeitura Municipal de Canoas;

COOPERMAG - a Associação de Triagem e Reciclagem Mato Grande (ATREMAG) surgiu em 2001 a partir da necessidade de encontrar uma alternativa para a geração de trabalho e renda para mulheres da comunidade Santa Rita, no Bairro Mato Grande (Canoas, RS). A Unidade de Triagem foi construída em 2001 com recursos da Caixa Econômica Federal. Na época, iniciaram o recebimento da coleta seletiva do munícipio. Em 2010, foram contratados para participar no Programa de Coleta Seletiva Compartilhada de Canoas, juntamente com COOARLAS, RENASCER e COOPCAMATE. Fundaram no mesmo ano a Cooperativa de Coleta Seletiva e Reciclagem União Faz a Força de Canoas (COOPERMAG);

ATPSCR-NSR - a associação foi fundada em 11 de setembro de 2005, visando à geração de trabalho e renda das pessoas envolvidas. A partir de 2010, foi construída uma parceria com a Prefeitura Municipal de Nova Santa Rita, RS, que doou a área para a sede, e ocorreu a projeção de parceria com Unilasalle e empresas para construir o galpão. Em outubro de 2011, foi construído o galpão de triagem e iniciou-se a coleta seletiva em alguns bairros do município de Nova Santa Rita.

\section{ANÁLISE E DISCUSSÃO DOS DADOS}

A análise das evidências demonstra que a maioria dos cooperados está preocupada com o atingimento de metas de produção durante a maior parte do tempo de seu trabalho. A busca constante pelo atingimento das metas de produção por todos os trabalhadores é uma das características da estratégia como prática, para a qual interessa a maneira como as tarefas são realizadas (WHITTINGTON, 1996). Essa evidência pode ser verificada na fala da E2 da COOPER A: "geralmente é assim entre nós mesmos, daí já tá acostumado, chega já começa trabalhando um com o outro, vai se dando bem, a produção tá boa vai mantendo...". Nesse sentido, pode-se observar que a preocupação com as metas estratégicas não são somente da coordenação da cooperativa. Um dos principais aspectos que conduz a esse comportamento é o fato de que a renda mensal depende da produção de todos os cooperados.

Outra evidência de que a estratégia como prática se revela no pensar e no agir estrategicamente (WILSON; JARZABKOWSKI, 2004) consiste no exemplo citado pela E1 da COOPER A: "aqui geralmente [...] tem as reunião, quando a gente tem alguma coisa assim [um problema], a gente se reúne, e é sempre resolvido, é achado alguma solução, se não é achado na hora a gente tenta buscar". Pode-se entender que a busca pela solução dos problemas ocorre de maneira conjunta, por meio da parada do trabalho nas mesas e da realização de uma reunião na cooperativa, em que todos buscam uma solução de maneira coletiva por meio dos processos democráticos de participação (SINGER, 2002).

Observa-se ainda que a Incubadora teve um papel importante para que a COOPER A conseguisse crescer. A Incubadora não forneceu somente o suporte legal e de organização do trabalho, mas também se preocupou de maneira global com os indivíduos que ali trabalhavam, inclusive no que diz respeito aos aspectos psicossociais. Isso pode ser observado na narração da E1 da COOPER A:

"Olha uma vez até foi engraçado que o Robinson implantou aqui, ele fez uma dinâmica 
sobre os anjos né, as anjas, eu sei que nós tinha até asa nós tinha, agora consumiram com as nossas asas, ele dizia pra uma cuidar a outra sabe, então cada uma tinha a sua anja que cuidava de si e ao mesmo tempo era anja de outra. Então aquilo foi muito bom, bah um tempão sabe, a gente via nossa colega, nem pedia sabe e tava sempre olhando, então foi muito legal aquilo, só que depois foi perdendo, foi passando o tempo, foi saindo, não tinha muita gente sabe eu acho que do grupo que tem aqui umas quatro eu acho são daquela época sabe!"

Identificam-se questões sobre certa ambivalência entre as capacitações e reuniões que a Incubadora fazia na COOPER D. Alguns associados gostavam e valorizavam o aprendizado e a interação, mas outros não gostavam e achavam que estavam, de alguma maneira, perdendo produção e tempo. Observa-se isso na fala da E2 da COOPER D:

"Que muitos não entendiam o que era a Incubadora, é mas eu sempre gostava quando eles vinham né, porque daí a gente ficava conversando, entendendo os negócios da cooperativa, uns não gostavam, 'não entendo nada, o que que eu quero, tem que trabalhar, nós tem que produzir pra nós ganhar né', não gostava de ficar parado."

Nesse sentido, verifica-se que, para alguns associados, participar de reuniões e capacitações da Incubadora era perda de tempo e de produção, embora outros vissem tais momentos como oportunidades de crescimento. Deve-se salientar que, para a estratégia como prática, os dois aspectos são importantes: é preciso a interação entre o pensar e o agir de maneira estratégica. Por acaso ou não, a maioria do grupo se engajou na proposta da Incubadora, e a COOPER D desenvolveu-se consideravelmente, aumentando em $50 \%$ a sua renda, conforme as observações realizadas.

Observa-se que a Incubadora realizou um trabalho de empoderamento às cooperativas, uma vez que há evidências de que os cooperados não ficaram dependentes do trabalho da Incubadora. Isso pode ser percebido na fala a seguir: "Eu acho que é porque a gente já consegue caminhar com as próprias pernas, né, eles já nos ensinaram um pouco, já dá pra gente trilhar o caminho certo" (E2 da COOPER A).

Em vários depoimentos, percebe-se a valorização do suporte que a Incubadora deu às cooperativas incubadas, conforme o Quadro 02:

Quadro 02: Depoimentos sobre o papel da Incubadora.

\begin{tabular}{|c|c|c|}
\hline Empreendimento & Expressões das entrevistas & Informante \\
\hline COOPER B & $\begin{array}{l}\text { "Divulgar muita coisa assim sabe animar a gente, levantar a moral da } \\
\text { gente pra ir trabalhar. Dar mais ânimo". }\end{array}$ & E1 \\
\hline COOPER B & $\begin{array}{l}\text { "[...] eles limparam tudo, unimos todos, dai nós limpamos, dai ficou } \\
\text { bom, ali era tudo fechado aquela porta ali era fechada dai a pessoa } \\
\text { ficava triste". }\end{array}$ & E2 \\
\hline COOPER B & "[...] ajudou assim nós nos negócios que tinha um monte de dívida”. & E2 \\
\hline COOPER C & $\begin{array}{l}\text { "Ah, a gente teve muita ajuda, né. No caso, fomos bem ajudados. O } \\
\text { grupo quando tava mais agitado, né, a Lurdes vinha, conversava." }\end{array}$ & E1 \\
\hline COOPER C & $\begin{array}{l}\text { "Ah, pra nós mudou muita coisa porque o pessoal soube mais se } \\
\text { respeitar, conversar melhor. Nós tivemos aquelas palestras de mate- } \\
\text { riais, que foi explicado pra nós". }\end{array}$ & E1 \\
\hline COOPER D & $\begin{array}{l}\text { "[...] quando tinha esses problemas com o grupo, porque vinha a Lur- } \\
\text { des e os outros tentam conversar né, apaziguar. E ajudaram muito." }\end{array}$ & E2 \\
\hline COOPER E & $\begin{array}{l}\text { "[...] eles [o pessoal da Incubadora] dão várias ideias boas pra nós, } \\
\text { graças a eles também, e pra mim cada vez que vem uma pessoa que } \\
\text { dá opinião pra gente, né, hoje em dia no serviço, é muito bom”. }\end{array}$ & E1 \\
\hline
\end{tabular}


ESTRATÉGIA COMO PRÁTICA E APRENDIZAGEM NA INTERAÇÃO DOS SUJEITOS RECICLADORES: RESULTADOS DA INCUBADORA DE EMPREENDIMENTOS SOLIDÁRIOS, DO CENTRO UNIVERSITÁRIO LA SALLE, CANOAS, RS

\begin{tabular}{|c|c|c|}
\hline Empreendimento & Expressões das entrevistas & Informante \\
\hline COOPER A & $\begin{array}{l}\text { "[...] eles [o pessoal da Incubadora] trouxeram umas palestras, essas } \\
\text { coisas que eles vem nos trazendo, foi, foi importante, porque a gen- } \\
\text { te aprendeu como lidar com as pessoas, mais, um jeito melhor de } \\
\text { tratar as pessoas". }\end{array}$ & E2 \\
\hline COOPER F & $\begin{array}{l}\text { "[...] gostei muito e continuo gostando porque antigamente aqui } \\
\text { a gente não era visto, a gente não era enxergado, como é, não era } \\
\text { visto, [...] não vinha ninguém, nós oito horas ia lá pra cima [para o } \\
\text { lixão], de tarde largava e ia pra casa, eu acho que eu dizia assim: mas } \\
\text { ninguém sabe que nós existimos, ai dum anos pra cá, começaram, } \\
\text { dai as pessoas inclusive [...]começaram a enxergar nós duma manei- } \\
\text { ra que a gente achava que nunca ia ser". }\end{array}$ & E2 \\
\hline COOPER F & $\begin{array}{l}\text { "[...] a incubadora ela abre os novos horizontes pra gente, tira os } \\
\text { nós das vendas que estavam nos nossos olhos, esclarece muita coisa, } \\
\text { facilita muita coisa pra gente, capacitação intelectual e profissional". }\end{array}$ & E4 \\
\hline COOPER A & $\begin{array}{l}\text { "Eu participei de várias palestras de várias coisas da Incubadora e eu } \\
\text { gostei de todas elas, entendeu. Aquela coisa assim de tu te preocu- } \\
\text { par com as pessoas de ensinar de como tu liderar uma..., até a mi- } \\
\text { nha própria vida mesmo, entendeu. E, sei lá, ajudar a pensar melhor, } \\
\text { entendeu. Sempre tem, sempre mostra pra gente os, tem como lidar } \\
\text { com aqueles problemas mais difíceis, uma coisa difícil, entendeu. Eu } \\
\text { gosto de todos que passaram por nós, né". }\end{array}$ & E3 \\
\hline COOPER G & $\begin{array}{l}\text { "Acho que a esperança do maquinário, de dar a oportunidade de ga- } \\
\text { nhar mais dinheiro, entendeu, que sem o maquinário, fica difícil que } \\
\text { a gente vende o material, a gente não tem a certeza que o material } \\
\text { está sendo valorizado pelo que ele é, entendeu". }\end{array}$ & E1 \\
\hline COOPER F & $\begin{array}{l}\text { "[...] eu vejo como um trabalho bastante positivo, do tempo que eu } \\
\text { tô aqui, eu vejo só como, assim, só pra levantar mesmo, porque vá- } \\
\text { rios momentos que as cooperativas passaram. A nossa foi uma que } \\
\text { teve um pouquinho, acho que uns dois anos e pouco atrás, que foi } \\
\text { mudando, que era associação e passou para cooperativa, teve um } \\
\text { trabalho muito forte da Incubadora ajudando nisso, né. Em docu- } \\
\text { mentação, orientação de que fazer, como fazer, onde fazer. [...] A In- } \\
\text { cubadora teve um papel muito importante, sim, para ajudar". }\end{array}$ & E3 \\
\hline COOPER E & $\begin{array}{l}\text { "Eles criaram um trabalho para nos informar e nós nos formar, agora } \\
\text { tão se formando, mas tinha que ter um acompanhamento básico, né, } \\
\text { pra dar uma olhadinha como tão, nos papéis se estão organizados } \\
\text { mesmo, porque isso aí, internet pra catador é [...] Eu sou uma que, } \\
\text { internet pra mim, isso aí é outro mundo, né. Então vim ver se tá } \\
\text { certo, fazer um acompanhamento, não precisa ser toda hora, toda } \\
\text { semana, mas de uma vez na semana, a Incubadora tem que tá junto } \\
\text { com a gente. Foi uns } 6 \text { meses o caminho da cooperativa, né, um ano, } \\
\text { porque não é assim que formou e largou, vamos fazer um acompa- } \\
\text { nhamento para ver como vai andar, né, um apoio ainda na forma- } \\
\text { ção". }\end{array}$ & E2 \\
\hline
\end{tabular}

Fonte: elaborado pelos autores.

Frente a esses depoimentos, evidencia-se que há mecanismos simbólicos e concretos de verificação de estratégias como práticas no trabalho de incubação realizado, uma vez que são identificados momentos que demostram as práticas realizadas e os diálogos (FREIRE, 2004), bem como os resultados do processo de assessoria, o que indica, evidentemente, a metodologia de trabalho adotada (CANÇADO; CANÇADO, 2009).

Ficou evidente que os processos de aprendizagem são constantes e fomentados pelo ambiente do trabalho coletivo. Pode-se observar grande aprendizado no seguinte depoimento:

“Há uns tempo atrás houve uma fofoca, das gurias, no caso das líderes né... Aí nós subimos aqui [andar de cima] e cada uma falou o que achava sobre o que tinha acontecido. Foi esclarecido e foi visto que tinha sido só fofoca de gente que nem trabalha aqui... Eu era 
muito de resolver as coisas... Tipo ignorante, né. Aí eu aprendi a conviver melhor com as gurias. Até conviver melhor em casa. Se tem um problema, a gente senta e conversa. Antes não era assim, eu estourava e saía gritando e fazendo... Antes dava um problema, dava uma encrenca, estava brigando. Agora não, aconteceu isso, isso e isso que eu não gostei, tá, então, vamos tentar melhorar. Daí é melhor. Eu acho que a gente não pode dizer exatamente porque chegamos aqui, a gente entra no ritmo das gurias daqui. Então eu acho que tem que ser aberto para as novidades." (E3 da COOPER D).

Pode-se observar nesse relato o potencial transformador e educativo da economia solidária. Segundo Adams (2010), as pessoas aderem ao processo de economia solidária por força das circunstâncias, e não porque estão identificadas com o potencial educativo e transformador da mesma. Mas, à medida que vão experienciando essas práticas de relações coletivas e autogestionárias, vão se apercebendo do lugar que estão ocupando e, consequentemente, reconhecendo-se como educadores de base popular que têm no chão do trabalho associado elementos para composição de uma pedagogia da autogestão. A partir daí, torna-se possível a compreensão da economia solidária como local privilegiado da educação popular. Observa-se que os trabalhadores envolvidos em empreendimentos solidários apreendem a solidariedade vendo os demais trabalhadores com outra consciência social valorizarem-se de forma independente em relação ao trabalho realizado. As pessoas reaprendem a valorizar o que é feito e o ambiente em que vivem. Esse aspecto pode ser verificado na fala da E3 da COOPER F:

"Eu era mais acostumada na minha casa, ali só, saía do serviço e voltava para casa, não tinha nem assim, muito contato de tá conversando com as pessoas na rua e aqui, eu conheci, assim, histórias de pessoas que aqui trabalham há 30 anos, é mais tempo que a minha idade... A gente vê que eles sentem prazer em trabalhar com isso, e que o que eu tento mostrar para as pessoas é tirar esta coisa de marginalizar quem trabalha com lixo ou cata na rua."

Os processos de aprendizagem, fomentados pela educação popular e vivenciados no dia a dia dos cooperativados, podem ajudar a formar um sentido para o trabalho (CANÇADO; CANÇADO, 2009). Um exemplo é a seguinte fala, de uma das cooperativadas:

"Aprendi a dar valor para o material reciclado, que, lá em casa, eu misturava tudo, botava tudo fora. Que a gente tá prejudicando o meio ambiente, né. Sem contar o aterro sanitário, que tá, cada vez mais, enchendo por culpa da população, que não tem consciência que está poluindo o ar que ela respira" (E3 da COOPER E).

Essas evidências mostram que, quando um empreendimento participa e trabalha de acordo com os princípios da economia solidária, a visão dos trabalhadores amplia-se. Esses trabalhadores passam a valorizar seu espaço e a pensar o local de trabalho como um todo responsável pela ligação da vida cotidiana com a natureza. A Incubadora contribui para a melhor compreensão do grupo em relação ao cooperativismo. Tal contribuição pode ser atribuída ao trabalho desenvolvido, tanto dentro das cooperativas como por meio de cursos e oficinas oferecidos para diversos cooperados, propiciando, também, a melhoria das relações nos grupos. O relato a seguir pode exemplificar esse aspecto:

"Eu aprendi bastante coisa, até mesmo os cursos que a gente faz assim sabe. Ate assim ajudar, ser cooperativo com o outro. [...] E amizade, e ser sincero uma com a outra, tudo isso a gente, sabe aqui a gente ao menos tenta né, conversar bastante" (E1 da COOPER A). 
Outra cooperada também destaca como seu aprendizado a partir do trabalho da Incubadora a ajuda nas relações com seu grupo de trabalho:

\begin{abstract}
"O que eu mais, o que eu mais aprendi, o que eu mais aprendo acho que é respeitar o limite dos outros, todo mundo tem o seu limite, então, respeitar os limites. Respeitar qualquer um acho que respeitar do mesmo jeito que tu quisesse ser respeitado" (E3 da COOPER A).
\end{abstract}

Quando analisadas essas evidências, recorre-se a Adams (2010), que afirma que como espaço de mediações pedagógicas o mundo do trabalho perpassa todas as dimensões da vida como um conjunto complexo de interações. Nesse sentido, o trabalho associado favorece, em função do seu caráter autogestionário, a intervenção de coletivos de trabalho como sujeitos do processo de formação humana em vista de uma crescente autonomia, especialmente quando há uma unidade articulada de um universo que é simultaneamente técnico, social e cognitivo.

As evidências indicam que a Incubadora atuou como propulsora de políticas públicas. Os entrevistados sinalizam em suas falas que, no decorrer do trabalho da Incubadora, algumas parcerias com o poder público foram desenvolvidas a partir de discussões sobre as necessidades dos empreendimentos. Exemplo disso é o caso da Cooperativa Cootre de Esteio que, no decorrer de 2012 e 2013, criou um GT com membros da Prefeitura Municipal de Esteio e da Incubadora de Empreendimentos Solidários de Canoas para a construção de modelo de contrato de prestação de serviço para a coleta e triagem dos resíduos sólidos urbanos da cidade.

\footnotetext{
“O trabalho nosso tá bom, tá bem, tá, tá. A prefeitura tá fazendo parceria com nós, da maneira deles, mas tá sendo parceiro, porque tem aí gestores públicos que nem tão dando assunto para as cooperativas. O grupo todo nosso aqui, todos são acessíveis a escutar e a aprender, sabe, a nova ideias, vamos buscar informações. Estamos certos, estamos errados? E até hoje a Incubadora sempre nos apoiou e não erramos tivemos educação para falar com os gestores, saber se colocar com os gestores públicos [...]" (E2 da COOPER E).
}

Por meio dessa forma de aprendizado voltado para a negociação e para o empoderamento dos participantes, verifica-se que a Incubadora elabora mecanismos de formação popular que permitem o fortalecimento das cooperativas, tanto no acesso às políticas públicas e ao debate com os governos quanto na construção de redes de cooperação, conforme demonstra o diário de campo de 01 de agosto de 2013:

Na reunião da Coopercan [Central das Cooperativas de Materiais Recicláveis de Canoas], os dirigentes organizaram um projeto piloto de comercialização de metais em conjunto, sendo que uma ação inicial é a de pesquisar indústrias recicladoras que comprem esse tipo material e negociar preço e volume para a possível comercialização em rede. As questões pertinentes ao valor a ser depositado no fundo vai depender dessa negociação, bem como o resultado dessa operação de venda coletiva.

Esses avanços nas atividades coletivas e em rede são frutos de um longo trabalho de formação junto aos empreendimentos incubados, além de visualização das potencialidades que os catadores possuem no processo de desenvolvimento de seu trabalho, objetivando melhores condições de vida. 


\section{RESULTADOS E DESAFIOS FUTUROS}

A partir da análise realizada foi possível depreender que o papel que uma ITCP desempenha não é único e exclusivamente voltado para os empreendimentos de economia solidária. Ela valoriza o conhecimento do campo acadêmico e a prática da pesquisa, buscando, assim, a conexão com a realidade socioambiental em que as cooperativas operam, além de desenvolver mecanismos de participação nas políticas públicas em prol da economia solidária. No que se refere à pesquisa, verificou-se que muitas das ações desenvolvidas pela Incubadora ficaram pouco evidenciadas nas entrevistas, pois o leque de atuação é tão abrangente que os participantes acabam percebendo as questões mais objetivas das práticas internas de trabalho. É justamente no avanço da organização das práticas de trabalho, seja em termos físicos com os materiais e maquinários, seja em termos psicossociais ou mesmo em termos da auto-organização em busca das metas de produção e da resolução de problemas, que a estratégia como prática pode se revelar. Além disso, algumas análises indicam que os aspectos de ampla atuação também foram percebidos e valorizados, demonstrando o escopo de abrangência da Incubadora, como, por exemplo, no que se refere às políticas públicas.

Portanto, a partir dos resultados do presente artigo torna-se possível identificar que: i) a atuação da Incubadora é avaliada como sendo propulsora de políticas públicas por meio dos processos democráticos de participação; ii) a construção dos processos de aprendizagem foi realizada por meio da educação popular; e iii) há necessidade da ampliação da ação da Incubadora para além dos empreendimentos incubados, na busca de redes de cooperação para o fortalecimento da cadeia produtiva da reciclagem, intentando o beneficiamento dos resíduos sólidos urbanos, a comercialização conjunta e a construção de laços de solidariedade.

Enfim, os mecanismos de desenvolvimento do trabalho de assessoria são promovidos pelas interações com os cooperados que fazem parte dos empreendimentos no exercício dialógico de (re)produção dos práticas de economia solidária. As interações sociais estabelecidas por meio dos vínculos construídos permitem, em graus variados, o desenvolvimento da educação popular, das práticas de produção no campo da reciclagem, das práticas de autogestão e participação democrática, do respeito, dentre outros. Enfim, nesse campo de atuação, percebe-se que a estratégica como prática pode ser evidenciada com maior facilidade do que em campos organizacionais, uma vez que os participantes unem esforços em prol do bem comum, pensando e agindo em sintonia e em sincronia. Além disso, a permanência e a continuidade da assessoria, mesmo que na pós-incubação, permite o desenvolvimento dos empreendimentos econômicos solidários, bem como a criação de estratégias como práticas que possibilitem a adequação dos cenários de desigualdades e a elaboração de políticas públicas que consolidem as práticas de economia solidária. 
ESTRATÉGIA COMO PRÁTICA E APRENDIZAGEM NA INTERAÇÃO DOS SUJEITOS RECICLADORES: RESULTADOS DA INCUBADORA DE EMPREENDIMENTOS SOLIDÁRIOS, DO CENTRO UNIVERSITÁRIO LA SALLE, CANOAS, RS

\section{REFERÊNCIAS}

ADAMS, Telmo. Educação e economia popular solidária: mediações pedagógicas do trabalho associado. Aparecida, SP: Idéias \& Letras, 2010.

ANTUNES, Ricardo; POCHMANN, Marcio. A desconstrução do trabalho e a explosão do desemprego estrutural e da pobreza no Brasil. In. CIMADAMORE, Alberto D.; CATTANI, Antonio D. (Orgs.). Produção de pobreza e desigualdade na América Latina. Porto Alegre: CLACSO/Tomo Edit, 2007, p. 195-210.

ASSEBURG, Hans B.; GAIGER, Luiz I. G. A economia solidária diante das desigualdades. Dados, Rio de Janeiro, v. 50, n. 3, p.499-533, 2007.

BALESTRIN, Alsones \& VERSCHOORE, Jorge. Redes de cooperação. Estratégias de gestão na nova economia. Porto Alegre: Bookman, 2008.

BARDIN, Laurence. Análise de Conteúdo. Lisboa: Edições 70, 1977.

BAUER, Martin; AARTS, Bas. A construção do corpus: um princípio para a coleta de dados qualitativos. In. BAUER, Martin; GASKELL, George. Pesquisa Qualitativa com Texto, Imagem e Som. Petrópolis: Vozes, 2002. p.3963.

BOURDIEU, Pierre. A Distinção: crítica social do julgamento. São Paulo/Porto Alegre, EDUSP: Zouk, 556 p, 2007.

BRASIL. Ministério do Trabalho e Emprego. Atlas de Economia Solidária no Brasil, Brasília: Secretaria Nacional de Economia Solidária, 2007.

CANÇADO, Airton Cardoso e CANÇADO, Anne Caroline Moura Guimarães. Incubação de cooperativas populares: metodologia dos indicadores de desempenho. 2. ed. Palmas -TO: Futura, 2009.

CHESBROUGH, H. Management Innovations for the Future of Innovation. Ivey Business Journal. May / June, 2011.

CROSSAN, Mary; LANE, Henry; WHITE, Roderick. An organizational learning framework: fromintuition to institution. Academy of Management Review, v. 24, n. 3, p. 522-537, Jul 1999.

DELLA VECHIA, Renato et. al. A Rede de Itcps - passado, presente e alguns desafios para o futuro. Diálogo. Canoas. n. 18, p.115-144, janjun 2011.

FIOL, M. e LYLES, Organizational learning. Academy of Management. The Academy of Management Review (pre-1986); Oct 1985; p. 803-813.

FISCHER, Nilton Bueno. Perplexidades, Desafios e Propostas na Educação Ambiental a partir da Trajetória de um Pesquisador. Revista Educação e Realidade. UFRGS, v. 34, p. 25-39, set/dez 2009.

FRANÇA FILHO, Genauto Carvalho; CUNHA, Eduardo Vivian. Incubação de redes de economia solidária. In: HESPANHA, Pedro et. al. Dicionário Internacional da Outra Economia. São Paulo: Almedina Brasil, 2009, p. 224-230.

FREIRE, Paulo. Pedagogia da Autonomia: saberes necessários à prática educativa. 30a edição. São Paulo: Paz e Terra, 2004.

GAIGER. Luiz Inácio. Sentidos e experiências da economia solidária no Brasil. Porto Alegre: Editora da UFRGS, 2004.

GAIGER, Luiz Inácio. Relações entre equidade e viabilidade nos empreendimentos solidários. Lua Nova. São Paulo, n. 83, p.79-109, 2011.

GIL, Antonio Carlos. Métodos e técnicas de pesquisa social. 5.ed. São Paulo: Atlas, 1999.

LEITE, Paulo Roberto. Logística Reversa: meio ambiente e competitividade. São Paulo: Pearson Prentice Hall, 240 p, 2009.

LISBOA, Armando de Melo. A socioeconomia 
solidária diante da grande transformação. Ciências Sociais Unisinos, São Leopoldo, v.37, n.159, p.27-57, 2001.

LOPES, José Rogério. Processos sociais de exclusão e políticas públicas de enfrentamento da pobreza. Caderno CRH. Salvador, v. 21, n. 53, p, 349-363, 2008.

MEIRELES, M.E.; ALVES, J.C.M. Gestão de Resíduos: As possibilidades de construção de uma rede solidária entre associações de catadores de materiais recicláveis. In.: VII Congresso Nacional de Excelência em Gestão. Rio de Janeiro. 2011.

ROESCH, Sylvia Maria Azevedo. Projetos de Estágio e de Pesquisa em Administração: guia para estágios, trabalhos de conclusão, dissertações e estudos de caso. 3.ed. São Paulo: Atlas, 2005.

SINGER, Paul. Introdução à Economia Solidária. São Paulo: Fundação Perseu Abramo, 2002.

VERONESE, Marília Veríssimo. A psicologia na transição paradigmática: um estudo sobre o trabalho na economia solidária. Porto Alegre: PUCRS, 2004. 226f. Tese (Doutorado em Psicologia), Pontifícia Universidade Católica do Rio Grande do Sul - PUCRS, Porto Alegre, 2004.

WEICK, Karl; WESTLEY, Francis. Aprendizagem Organizacional: confirmando um oxímoro. In: CLEGG, Stewart R.; HARDY, Cynthia; NORD, Walter R. (orgs.) Handbook de estudos Organizacionais. São Paulo: Atlas, 2004. v. 3, p. 361-388.

WHITTINGTON, Richard. Strategy as practice. Long Range Planning, v. 29, n. 5, p. 731- 735, 1996.

WHITTINGTON, Richard. Estratégia após o modernismo: recuperando a prática. Revista de Administração de Empresas. v. 44, n. 4, 2004.

WILSON, E; JARZABKOWSKI, P. Pensando e agindo estrategicamente: novos desafios para análise estratégica. Revista de Administração de Empresas. v. 44, n. 4, 2004.

YIN, R. K. Estudo de Caso: planejamento e métodos. 3. ed. Porto Alegre: Bookman, 2005. 
ESTRATÉGIA COMO PRÁTICA E APRENDIZAGEM NA INTERAÇ̃̃O DOS SUJEITOS RECICLADORES: RESULTADOS DA INCUBADORA DE EMPREENDIMENTOS SOLIDÁRIOS, DO CENTRO UNIVERSITÁRIO LA SALLE, CANOAS, RS 
ROBINSON HENRIQUE SCHOLZ GRACIEMA FÁTIMA DA ROSA MARIA DE LOURDES BORGES 
ESTRATÉGIA COMO PRÁTICA E APRENDIZAGEM NA INTERAÇ̃̃O DOS SUJEITOS RECICLADORES: RESULTADOS DA INCUBADORA DE EMPREENDIMENTOS SOLIDÁRIOS, DO CENTRO UNIVERSITÁRIO LA SALLE, CANOAS, RS 